\title{
EVALUATION OF A PNEUMOTACHOGRAPH FOR CONTROLLED VENTILATION IN CHILDHOOD*
}

\author{
J. B. OWEN-THOMAS, M.B., GH.B., M.D.(LVVERP.), F.F.A.R.C.S.(ENG.)†
}

IN ORDER TO EVALUATE the effect of intermittent positive pressure ventilation (I.P.P.V.) on blood gas changes in childhood during general anaesthesia measurement of minute volume is essential. Instruments such as the respiratory anemometer, ${ }^{1,2}$ are not, at present, suitable for paediatric work, since below flow rates of $3.8 \mathrm{~L} . / \mathrm{min}$., and at rates of breathing above 40 per minute, grave errors of measurement occur. ${ }^{3,4}$

An appartus used to measure minute volume in infants and children must have a minimum of dead space and must be accurate. One which can be used with conventional anaesthetic circuits is desirable, and the T-piece pneumotachograph described by Lunn, Molyneux, and Pask, ${ }^{5}$ for use during general anaesthesia with spontaneous ventilation has these advantages. This paper describes the modification and evaluation of a similar instrument for use during conditions of controlled ventilation.

\section{METHOD}

The number of corrugations in the copper foil ( $F$ in Fig. 1) used for the flow resistance was increased by passing the foil between $I^{\prime \prime}$ diameter gear wheels with 60 teeth, producing a tube which divided the gas flow into a large number of parallel columns, the object being to avoid turbulent flow across the resistance during controlled ventilation.

Apparatus dead space must be kept to a minimum during spontaneous ventilation, to avoid rebreathing of expired carbon dioxide, but this consideration is less important during controlled ventilation involving passive pulmonary hyperventilation. An increase in dead space has therefore been accepted and in the present instrument is $8 \mathrm{ml}$. In all other features the construction of the instrument followed the description of Lunn et al. ${ }^{5}$

Following construction it was necessary to calibrate the pneumotachograph for linearity of response to steady flow and to check its capabilities in response to intermittent flow of air, and mixtures of nitrous oxide and oxygen, over the range of rates of ventilation to be met in practice.

\section{Calibration of Pneumotachograph}

The principle of calibration of the pneumotachograph is based upon the pressure differential across the copper resistance produced by the gas flow. ${ }^{6}$ This is a linear function of flow up to a limiting value, given by Reynolds number, ${ }^{7}$ and

-Part of a Doctor of Medicine thesis at the University of Liverpool.

†Registrar to the Intensive Therapy Unit, Alder Hey Children's Hospital, Liverpool, England. Currently Research Fellow, Department of Anaesthetics, Hospital for Sick Children, Toronto, Ontario. 


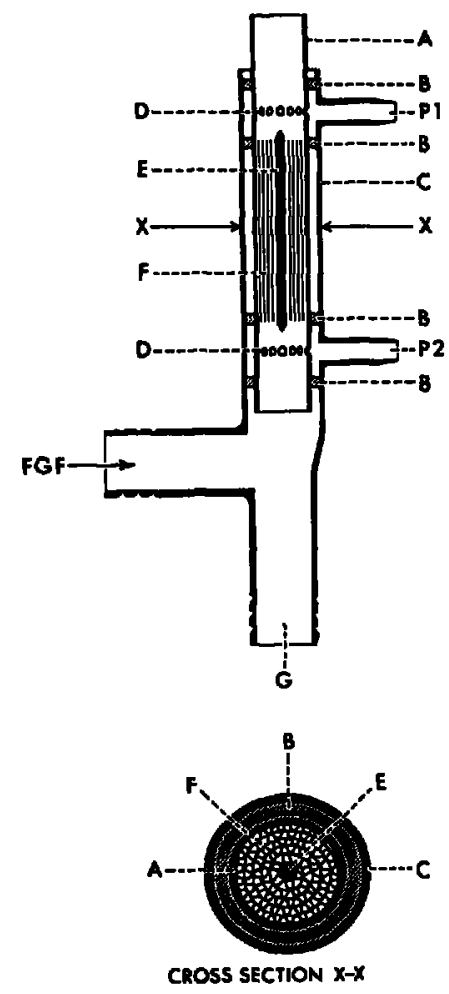

Figure 1. Horizontal and cross-section views of the pneumotachograph. A: inner tube; B: rubber seals; C: copper T-piece; $D$ : annular perforations; E: brass core; F: copper foil resistance; G: opening connected via corrugated tube to Rees openend bag; FGF: fresh gas flow; $P_{1}$ and $P_{2}$ : tapping points for differential pressure. Lateral view shown one-half actual size. (Modified after Lunn et al., 1965.)

is determined by the diameter of the tube, the velocity of the gas flow, and the gas viscosity. The linearity of the pneumotachograph in response to steady flow of air was, therefore, determined in the following sequence:

1. By alcohol inclined manometer.

2. By substituting the inclined manometer for a gas pressure transducer (Sanborn Model 270), electronically amplifying the signal produced by means of a four-channel recording instrument (Model 964, Sanborn Ltd., Waltham, Mass.), and noting the resulting deflection of the flow channel stylus on recording paper, in response to steady flow rates of air measured by rotameter.

\section{Linearity of Pneumotachograph by Alcohol Inclined Manometer}

The conventional U-tube water manometer suffers from the disadvantage that two readings are necessary. The difference between the two levels may be the difference between two large quantities. The inclined alcohol manometer aims at increased sensitivity and ease of reading, by keeping one surface level in the reservoir constant, and allowing movement of the alcohol meniscus to be greater than if it were vertically positioned. 
Errors due to the curvature of the meniscus are reduced by using a fluid of low surface tension, e.g. alcohol, and errors due to parallax are eliminated by placing a mirror behind the inclined tube and a sliding cursor in front. Conversion of the reading from alcohol to water is achieved by use of the hydrostatic equation, e.g. $\mathrm{cm}$. water $=\mathrm{cm}$. alcohol $\times$ density of alcohol.

Differential pressure across the pneumotachograph was measured by alcohol inclined manometer (Fig. 2), and flow with a rotameter calibrated at $15^{\circ} \mathrm{C}$.

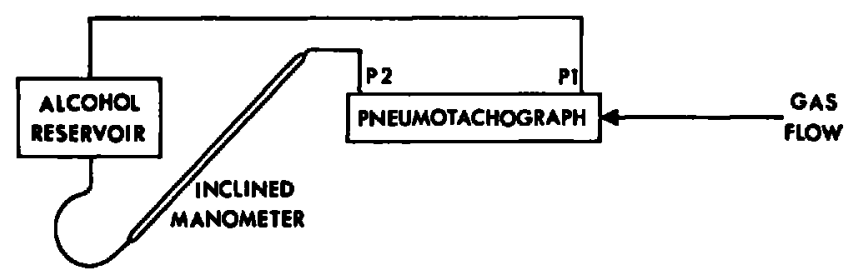

Ficune 2. Diagram of the apparatus used to measure differential pressure across the pneumotachograph in response to steady How of gas.

and $760 \mathrm{~mm} . \mathrm{Hg}$ to \pm 2 per cent accuracy by the manufacturer (Rotameter M.F.G., U.K.) over the range 0-40 L./min. Flow was varied in increments of $5 \mathrm{~L}$. The differential pressure across the pneumotachograph was measured by noting the change in level of the alcohol meniscus at each flow rate. The mean of ten observations at each flow rate (Table I) is shown in Figure 3. Mean

TABLE I

Conversion of CM. Alcohol to CM. Water

(Specific Gravity of Alcohol $=0.84$ )

\begin{tabular}{cccc}
\hline $\begin{array}{c}\text { Flow } \\
(\mathrm{L} . / \mathrm{min})\end{array}$ & $\begin{array}{c}\text { Mean pressure difference } \\
\text { (10 values) }\end{array}$ & $\begin{array}{c}\Delta \mathrm{P}-2 \\
\text { (cm. alcohol) }\end{array}$ & $\times 0.84=\mathrm{cm} . \mathrm{H}_{2} \mathrm{O}$ \\
\hline 0 & 2.0 & 0 & 0 \\
5 & 3.1 & 1.1 & 0.92 \\
10 & 4.4 & 2.4 & 2.0 \\
15 & 5.9 & 3.9 & 3.2 \\
20 & 7.6 & 5.6 & 4.7 \\
25 & 9.6 & 7.6 & 6.3 \\
30 & 11.8 & 9.8 & 8.2 \\
35 & 13.9 & 11.9 & 9.9 \\
40 & 16.4 & 14.4 & 12.0 \\
\hline
\end{tabular}

values for differential pressure are plotted against steady flow of air, and indicate a linear relationship for flows up to 20 to $25 \mathrm{~L} . / \mathrm{min}$. (Fig. 3).

The pneumotachograph was placed upstream of the same rotameter and the air flow was varied from 5 to $30 \mathrm{~L} . / \mathrm{min}$. in increments of $5 \mathrm{~L}$. Deflections of the flow channel stylus were observed in response to each flow rate. The means of 6 sets of observations are shown in Table II, and when plotted graphically the linearity observed is of the same order as that measured by inclined manometer, indicating that the electronic device was not distorting the signal. It was essential to test the ability of the pneumotachograph to respond to intermittent flow of gases of differing viscosities similar to the conditions to be met during I.P.P.V. 


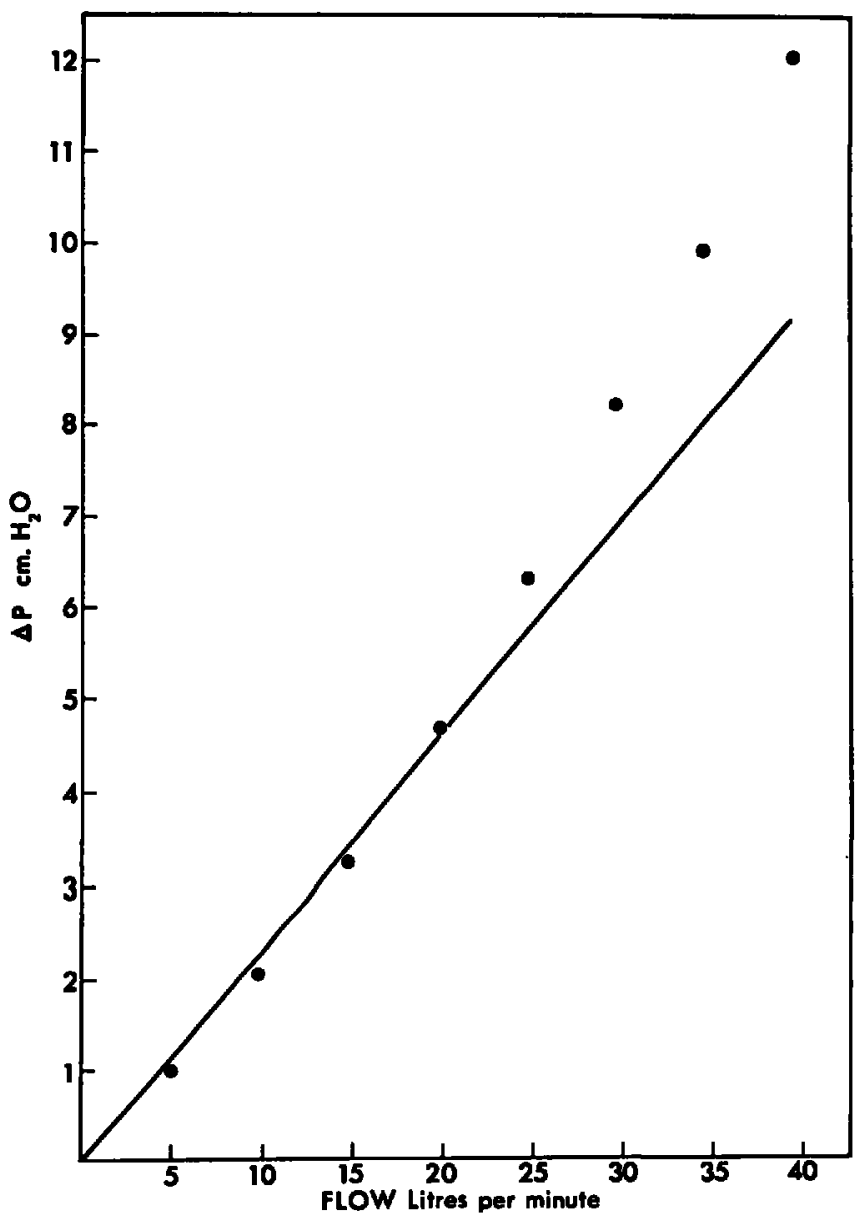

Ficure 3. Differential pressure plotted against steady flow. Response is linear up to flows between 20 and $25 \mathrm{~L} . / \mathrm{min}$.

TABLE II

Linearity of PNeumotachograph to Steady Flow of Air from Rotameter (M.F.G. R.522708)

\begin{tabular}{crrrrrrr}
\hline $\begin{array}{c}\text { Rotameter flow } \\
\text { (L./min.) }\end{array}$ & \multicolumn{10}{c}{ Flow preamplifier deflection (mm.) } \\
\hline 0 & & & & 0 & & & Mean \\
\hline 5 & $\mathbf{3 . 5}$ & 4.0 & $\mathbf{4 . 0}$ & $\mathbf{3 . 5}$ & $\mathbf{4 . 0}$ & $\mathbf{3 . 5}$ & $\mathbf{3 . 7}$ \\
$\mathbf{1 0}$ & $\mathbf{8 . 0}$ & $\mathbf{8 . 0}$ & $\mathbf{8 . 0}$ & $\mathbf{8 . 0}$ & $\mathbf{8 . 0}$ & $\mathbf{8 . 0}$ & $\mathbf{8} .0$ \\
$\mathbf{1 5}$ & $\mathbf{1 3 . 0}$ & $\mathbf{1 3 . 0}$ & $\mathbf{1 3 . 0}$ & $\mathbf{1 3 . 0}$ & $\mathbf{1 3 . 0}$ & $\mathbf{1 3 . 0}$ & $\mathbf{1 3 . 0}$ \\
$\mathbf{2 0}$ & $\mathbf{1 9 . 0}$ & $\mathbf{1 9 . 0}$ & $\mathbf{1 9 . 0}$ & $\mathbf{1 9 . 0}$ & $\mathbf{1 9 . 0}$ & $\mathbf{1 9 . 0}$ & 19.0 \\
$\mathbf{2 5}$ & $\mathbf{2 5 . 0}$ & $\mathbf{2 5 . 0}$ & $\mathbf{2 5 . 0}$ & $\mathbf{2 5 . 0}$ & $\mathbf{2 5 . 0}$ & $\mathbf{2 5 . 0}$ & $\mathbf{2 5 . 0}$ \\
$\mathbf{3 0}$ & $\mathbf{3 0 . 0}$ & $\mathbf{3 2 . 0}$ & $\mathbf{3 2 . 0}$ & $\mathbf{3 1 . 0}$ & $\mathbf{3 2 . 0}$ & $\mathbf{3 0 . 0}$ & $\mathbf{3 1 . 1}$ \\
\hline
\end{tabular}

with this instrument. Furthermore, it is necessary to use a simple device for calibration of the integrator prior to and during use, and this was carried out as follows. 


\section{Calibration of Syringe and Integrator}

A calibrated all-glass syringe was used, and known volumes of air passed through the pneumotachograph at rates of delivery similar to those to be met in practice. The value of the resulting integrator deflection in millimetres would be known ${ }^{8, \theta}$ allowing a comparison between the known volume delivered from the syringe and the volume obtained by integration.

Calibration of syringe. The syringe was calibrated by delivering volumes of distilled water from it at the 20,50 , and $100 \mathrm{ml}$. positions on the barrel and weighed in a $250 \mathrm{ml}$. grade A beaker of known weight. This was repeated five times for each volume and the mean reading obtained and found to be 18.3 , 45.5 , and $92.7 \mathrm{ml}$. respectively for the three volumes. By a process of trial and error, the most satisfactory combination of calibration setting for sensitivity on the flow preamplifier and integrating preamplifier was obtained in the following way.

The pen deflection on the flow channel recording system is a function of the signal obtained from the gas pressure transducer. Movement of the sensitivity control of the flow channel alters the deflection of the pen and also the voltage output of the signal to the integrator. This voltage output was measured by a voltmeter during I.P.P.V. of a patient with the pneumotachograph and T-piece apparatus. The sensitivity of the flow channel was adjusted so that the voltage recorded remained above 0.75 volt over the range of rates of ventilation that would be met in practice, because manufacturer's instructions indicated that flow output signals below 0.5 volt produced large errors on integration. The setting of the sensitivity control was then always kept the same.

Integrator channel sensitivity: area mode. When the integrator is used in the area mode, it records the instantaneous sum of the area under the inspiratory or expiratory flow curve, and allows measurement of volume. The sensitivity of the integrator is defined in terms of the volt-second. This is the output signal which represents the area under the flow curve.

The integrator was set to produce the following relationship between the range setting (volt/second), pen deflection, and measured volume.

$\begin{array}{ccc}\text { Volt/seconds } & \begin{array}{c}\text { Integrator pen } \\ \text { deflection }(\mathrm{mm} .)\end{array} & \text { Pen deflection }(\mathrm{ml} . / \mathrm{mm} .) \\ 1 & 86 & 5.3\end{array}$

This value was used throughout the experimental work carried out.

During all experimental work the instrument was adjusted in order to suppress D.C. interference from the mains supply. The reset control of the integrator permits measurement of volume to be controlled manually over a period of one minute, measured by stop clock.

Calibration of integrator. At the commencement of all experiments, the integrator was calibrated as follows: At a rate of 80 per minute, $45.5 \mathrm{ml}$. per stroke was delivered from the syringe for 10 strokes of the plunger. A total volume of 455 $\mathrm{ml}$. thus passed through the pneumotachograph and resulted in a corresponding deflection of $86 \mathrm{~mm}$. on the integrator channel.

$$
1 \mathrm{~mm} .=455 / 86=5.3 \mathrm{ml} \text {. }
$$


In addition, a larger volume at a slow rate was delivered from the syringe through the pneumotachograph. At a rate of 20 per minute, $92.7 \mathrm{ml}$. per stroke was delivered for 10 strokes of the syringe plunger, a total volume of $927 \mathrm{ml}$. resulting in a deflection of $172 \mathrm{~mm}$. on the integrator channel.

$$
1 \mathrm{~mm} .=927 / 172=5.3 \mathrm{ml} \text {. }
$$

\section{Measurement of. Intermittent Flow}

In order to check whether the pneumotachograph and integrator would measure

TABLE III

Reproductbility of Constant Volume Readings on Integration during INTERMITTENT FLOW

(Syringe volume $455 \mathrm{ml}$.)

\begin{tabular}{lccccc}
\hline \hline Rate (per min.) & 100 & 90 & 80 & 60 & 20 \\
Integrator readings (mm.) & 86 & 85 & 84 & 80 & 85 \\
& 87 & 85 & 84 & 82 & 83 \\
& 86 & 84 & 85 & 84 & 84 \\
& 89 & 85 & 84 & 85 & 84 \\
& 87 & 86 & 85 & 84 & 84 \\
& 89 & 86 & 83 & 84 & 84 \\
& 87 & 86 & 85 & 84 & 85 \\
& 86 & 86 & 85 & 84 & 85 \\
& 86 & 85 & 85 & 85 & 85 \\
Mean & 84 & 87 & 85 & 85 & 83 \\
Integrator, mean $\times 5.3(\mathrm{ml})$. & 85 & 87 & 85 & 84 & 85 \\
S.D. & 86 & 87 & 84 & 84 & 84 \\
& 86.5 & 85.6 & 84.5 & 83.7 & 84.2 \\
& 45 & 453 & 447 & 444 & 446 \\
& 1.85 & 1.45 & 0.39 & 2.2 & 0.84 \\
\hline
\end{tabular}

TABLE IV

REPRODUCIBILITY OF VARIABLE VOLUME REadings ON INTEgration DURING INTERMITTENT FLOW

\begin{tabular}{|c|c|c|c|}
\hline Rate (per min.) & 100 & 100 & 20 \\
\hline Integrator reading (mm.) & $\begin{array}{l}165 \\
167 \\
174 \\
172 \\
175 \\
172 \\
175 \\
167 \\
169 \\
168 \\
166 \\
167\end{array}$ & $\begin{array}{l}\mathbf{3 4} \\
\mathbf{3 2} \\
\mathbf{3 3} \\
\mathbf{3 2} \\
\mathbf{3 3} \\
\mathbf{3 4} \\
\mathbf{3 4} \\
\mathbf{3 3} \\
\mathbf{3 3} \\
\mathbf{3 4} \\
\mathbf{3 4} \\
\mathbf{3 4}\end{array}$ & $\begin{array}{l}171 \\
170 \\
177 \\
172 \\
175 \\
169 \\
174 \\
175 \\
174 \\
173 \\
175 \\
172\end{array}$ \\
\hline Mean & 169.7 & 33.3 & 173.0 \\
\hline Integrator, mean $\times 5.3(\mathrm{ml}$ ). & 899 & 176 & 916 \\
\hline S.D. & 3.7 & 0.34 & 2.3 \\
\hline Syringe (ml.) & 91.5 & 183 & 927 \\
\hline
\end{tabular}


volume during intermittent flow, a volume of $45.5 \mathrm{ml}$. of air was delivered from the calibrated syringe at rates of $20,60,80,90$, and 100 per minute measured by metronome (Table III). The syringe plunger abutted onto a calibrated wooden stop. The height in millimetres integrated at each rate for ten strokes of the syringe plunger was measured and repeated 12 times and the results are shown in Table III. A volume of $92.7 \mathrm{ml}$. per stroke was delivered from the syringe at 20 per minte for 10 strokes of the plunger and the procedure repeated 12 times, and in order to check the capability of the pneumotachograph to measure small volumes at fast rates, $18.3 \mathrm{ml}$. was delivered at 100 per minute. The integrated heights for 10 and 50 measured strokes of the syringe plunger measured are shown in Table IV. As an additional check on the pneumotachograph's capacity to measure volume, a calibrated spirometer was used to deliver known volumes of air through the pneumotachograph to allow comparison of spirometer volume with the volume obtained by integration.

\section{Comparison of Spirometer with Integrator Volumes}

Calibration of spirometer. A Winchester bottle containing water was connected to the inlet of a grade A litre flask. The outlet of the flask was connected to the spirometer and the closed system checked for leakage of air. The spirometer bell was depressed by hand and allowed to find its own level. Water was allowed to flow into the flask up to the meniscus, displacing $1 \mathrm{~L}$. of air into the spirometer. This was repeated 12 times and the reading in millilitres per millimetre were recorded. The mean value obtained was $1 \mathrm{~mm}$. $=20.7 \mathrm{ml}$., the spirometer bell factor.

A 4-ounce weight was placed on the spirometer bell and the tap leading to the pneumotachograph opened. After an arbitrary time, the tap was closed and the volume which had left the spirometer was compared with the volume

TABLE V

Direct Comparison of Spirometer Volumes with Pheumotachograph VOLUMES

\begin{tabular}{|c|c|c|c|c|}
\hline $\begin{array}{l}\text { Spirometer } \\
\text { reading (mm.) }\end{array}$ & $\begin{array}{c}\text { Volume } \\
\mathrm{mm} . \underset{(\mathrm{L} .)}{\times 20.7 \mathrm{ml}}\end{array}$ & $\begin{array}{l}\text { Integrator } \\
\text { reading (mm.) }\end{array}$ & $\begin{array}{l}\text { Volume, } \\
\mathrm{mm} . \times 55.3 \\
(\mathrm{~L} .)\end{array}$ & $\underset{(\%)}{\text { Error }}$ \\
\hline $\begin{array}{l}80 \\
72 \\
96 \\
76 \\
79 \\
96 \\
77 \\
99 \\
90 \\
67 \\
211 \\
209 \\
231 \\
208 \\
237 \\
247\end{array}$ & $\begin{array}{l}1.656 \\
1.490 \\
1.987 \\
1.573 \\
1.635 \\
1.987 \\
1.593 \\
2.049 \\
1.863 \\
1.386 \\
4.367 \\
4.326 \\
4.781 \\
4.305 \\
4.905 \\
5.112\end{array}$ & $\begin{array}{l}287 \\
267 \\
354 \\
284 \\
291 \\
359 \\
274 \\
361 \\
347 \\
254 \\
766 \\
770 \\
850 \\
771 \\
871 \\
908\end{array}$ & $\begin{array}{l}1.521 \\
1.415 \\
1.874 \\
1.505 \\
1.542 \\
1.902 \\
1.452 \\
1.913 \\
1.839 \\
1.346 \\
4.059 \\
4.081 \\
4.505 \\
4.086 \\
4.616 \\
4.812\end{array}$ & $\begin{array}{l}8.0 \\
5.7 \\
5.7 \\
4.3 \\
5.6 \\
4.2 \\
8.8 \\
6.2 \\
1.2 \\
2.8 \\
7.0 \\
5.6 \\
5.7 \\
5.0 \\
5.8 \\
5.8\end{array}$ \\
\hline
\end{tabular}


measured by the pneumotachograph. This was repeated 16 times with the results shown in Table $\vec{V}$.

Correction of pneumotachograph volumes for gases differing in viscosity. To enable the pneumotachograph to be used for the measurement of minute volume during anaesthesia with nitrous-oxide-oxygen mixtures, and since the flow deflection varies with the viscosity of the gas passing through the pneumotachograph, ${ }^{10}$ a comparison was made between the integrator deflection produced by volumes of room air, oxygen, and nitrous-oxide-oxygen mixtures. In order to measure accurate percentages of nitrous-oxide-oxygen mixtures, the rotameters of a Standard Boyle's anaesthetic machine (British Oxygen Company) were checked as follows:

The reading on a Beckman oxygen analyser (Model 777, no. 296778) in response to 100 per cent oxygen was found to be within the manufacturer's standard of accuracy. The zero of this analyser was placed on 21 per cent room air. The rotameters on a Standard Boyle's anaesthetic machine were set at 5 L./min. nitrous oxide and $5 \mathrm{~L}$./min. oxygen. The senior probe of a Beckman oxygen analyser was placed in the centre of the stream of gases emerging. Flows varying from 1 to $5 \mathrm{~L}$. $/ \mathrm{min}$. of the mixture were sampled. The experiment was repeated for a 75 per cent nitrous-oxide-oxygen mixture. For a 50 per cent mixture delivered by the flow meters, 49 per cent (mean of 14 values) contained oxygen as measured by the Beckman analyser, and for a 75 per cent mixture, 26 per cent (mean of 14 values), was measured as oxygen. This degree of accuracy was considered to be acceptable.

Calibration for gases of differing viscosities. The flow preamplifier and integrator were balanced in accordance with the manufacturer's instructions. The flow channel sensitivity was adjusted so that $45.5 \mathrm{ml}$. of room air delivered from a syringe by 10 strokes of the plunger at a rate of 80 per minute gave a deflection of $86 \mathrm{~mm}$. on the integrator channel. Therefore $1 \mathrm{~mm} .=5.3 \mathrm{ml}$.

A 5 L., leak-proof rubber bag was connected to the outlet of the previously calibrated Boyle's anaesthetic machine. The outlet of this rubber bag was connected by a polythene tube 3 feet in length and $y^{\prime \prime}$ in diameter to the pneumotachograph, placed in series with the calibrated glass syringe. The rubber bag, reservoir, pneumotachograph, and springe formed a closed circuit. The syringe could, therefore, be used to sample the contents of the rubber bag reservoir and volumes of this gas would pass across the resistance within the pneumotachograph.

For each gas, the reservoir bag was filled and flushed out 10 times to ensure adequate mixing and sampling of a representative volume of the gas mixtures within the reservoir bag. Prior to commencement of the measurement of volumes of gases obtained by integration, the syringe plunger was moved 20 times at a rate of 80 per minute, in order to flush the dead space of the apparatus with the contents of the reservoir. Actual measurement of volumes was then commenced immediately.

For each gas investigated, $45.5 \mathrm{ml}$. was passed through the pneumotachograph at a rate of 80 per minute for 10 strokes of the syringe plunger. This was repeated 10 times. The mean value of the integrator reading is shown in Table VI. 
TABLE VI

INTEgRator Deflection for 45.5 C.c. OF Gases of Differing Viscosity at a Rate of 80/min. for 10 Strokes of Syringe Plunger

\begin{tabular}{llllcc}
\hline \hline & Air & $\mathrm{N}_{2} \mathrm{O}$ & $\mathrm{O}_{2}$ & $50 \% \mathrm{~N}_{2} \mathrm{O}-\mathrm{O}_{2}$ & $75 \% \mathrm{~N}_{2} \mathrm{O}-\mathrm{O}_{2}$ \\
\hline & 86 & 80 & 90 & 85 & 82 \\
& 87 & 80 & 90 & 85 & 79 \\
& 86 & 79 & 88 & 86 & 82 \\
& 85 & 81 & 89 & 86 & 83 \\
& 84 & 80 & 91 & 86 & 85 \\
& 86 & 81 & 90 & 86 & 84 \\
& 84 & 81 & 92 & 85 & 83 \\
& 85 & 80 & 91 & 86 & 84 \\
Mean & 85 & 80 & 92 & 85 & 83 \\
Range & 85.2 & 80.1 & 90.3 & 85.6 & 83.1 \\
S.D. & $84-87$ & $79-81$ & $88-92$ & $85-86$ & $79-85$ \\
\hline
\end{tabular}

A graph of integrator pen deflection in millimetres against percentage composition of gas (Fig. 4), shows that the integrator deflection produced by a 50 per cent nitrous-oxide-oxygen mixture is almost identical with the deflection pro-

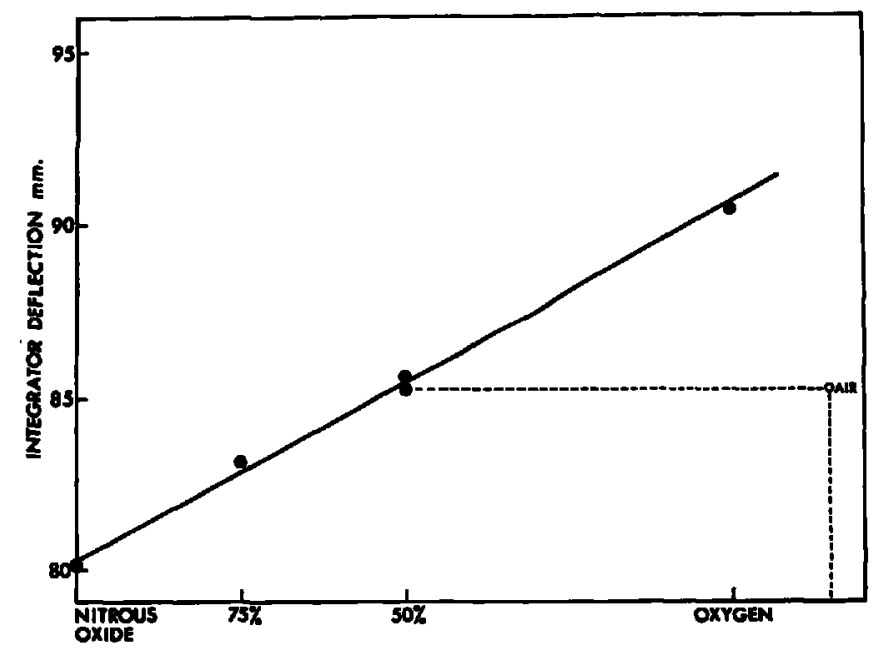

Frcure 4. Integrator deflection for gases of different viscosities passed through the pneumotachograph. The deflections for room air and for 50 per cent nitrous oxide and oxygen are almost identical.

duced by room air, and is in agreement with the work of Smith ${ }^{10}$ on the correction factor to be applied to gases of differing viscosities.

This offers a convenient method of calibrating the pneumotachograph using room air, whilst allowing its use with a 50 per cent mixture of nitrous oxide and oxygen for the measurement of patients' minute volumes during anaesthesia. It is reasonable to assume that the composition of expired gas during I.P.P.V. approxi- 
mates the inspired composition of 50 per cent nitrous-oxide-oxygen. In addition, volumes measured during I.P.P.V. of patients receiving 100 per cent oxygen as the inspired gas can be adjusted by a correction factor obtained from the ratio of integrator deflection of air to oxygen (Fig. 4).

\section{Discussion}

The results show that the present instrument has a linear pressure drop for flows up to 20 to $25 \mathrm{~L}$./min. This would permit minute volumes of approximately $8 \mathrm{~L}$. to be measured in practice, and would appear to be suitable for neonates and infants undergoing passive pulmonary hyperventilation during general anaesthesia.

Volumes obtained by integrating the flow signal from the pneumotachograph are lower than volumes leaving the spirometer with a percentage error ranging from 1.2 to 8.0 (Table V). However the pneumotachograph is intended for use under conditions of intermittent flow at higher peak flows than the gas leaving the spirometer. There is satisfactory agreement between volumes delivered from a calibrated syringe and volumes integrated (Tables III and IV) under conditions which approximate those to be met during I.P.P.V. Nevertheless it is essential to estimate, by statistical examination of the results, the error of measurement of minute volumes by the pneumotachograph for varying rates of ventilation (Tables III and IV).

The 2 per cent error of recycling of the integrated pen at rapid rates of ventilation is not accumulative. Statistical examination of the measurement of volumes at rates of ventilation of between 20 and 100 per minute, with reference to the standard deviation (Tables III and IV) reveals an error of $\mathbf{- 2 . 8}$ per cent stemming from the characteristics of the pneumotachograph. ${ }^{11}$

The coefficient of variation in the standard deviations expressed as a percentage of the mean of measurements at rates of 20 and 100 is given in Table VII. There

TABLE VII

Coefficients of Variation Based on Measurements ShOWN IN TABLE IV

\begin{tabular}{cccc}
\hline \hline Rate (min.) & Volume (c.c.) & Stroke & $\begin{array}{c}\text { Coefficient } \\
\text { of variation (\%) }\end{array}$ \\
\hline 100 & 18.3 & 10 & 0.18 \\
100 & 18.3 & 50 & 0.40 \\
20 & 92.7 & 10 & 0.25 \\
\hline
\end{tabular}

was, therefore, negligible bias in the estimated standard deviation, and satisfactory reproducibility of volumes at slow and fast rates. ${ }^{11}$

In order to predict the error of measurement of minute volume at rates above 100 per minute, it was established by extrapolation of the performance of the pneumotachograph, based on the estimated persistent bias at rates of $20,60,80$, 90 , and 100 per minute, that the error in reading volumes at rates between 100 and 200 per minute is +2 to 5 per cent. ${ }^{11}$ 
Temperature. The temperature of expired air is about $37^{\circ} \mathrm{C}$. The pneumotachograph would be calibrated at room temperature, but since the error introduced by this difference is less than the error involved in calibrating the pneumotachograph, ${ }^{8}$ in practice minute volume measurements need not be corrected for temperature.

Humidity. There are inherent practical difficulties in heating the pneumotachograph and controlling the temperature accurately, and the possible danger of a heated pneumotachograph close to a child's face and hidden beneath surgical drapes cannot be ignored. Furthermore, Lunn et al. have shown that protection against humidity is not necessary for periods up to 90 minutes.

Gas viscosity. The close approximation between the integrator deflection for a 50 per cent $\mathrm{N}_{2} \mathrm{O}-\mathrm{O}_{2}$ mixture and room air, described in the results and shown in Table VI and Figure 4, allows a convenient method of repeating the calibration procedure during the course of a study in the operating theatre. This instrument could therefore be used during general anaesthesia employing the d-tubocurarine$\mathrm{N}_{2} \mathrm{O}-\mathrm{O}_{2}$ hyperventilation sequence, adjusting the fresh gas flow to the patient to a 50 per cent $\mathrm{N}_{2} \mathrm{O}-\mathrm{O}_{2}$ mixture prior to study. This would obviate the need to introduce the gas viscosity correction factor described by Smith ${ }^{10}$ into the minute volume measurements obtained.

\section{SUMMARY}

A T-piece pneumotachograph has been evaluated experimentally to determine its suitability for use during controlled pulmonary hyperventilation. The pressure drop across the instrument is sufficiently linear per unit of flow to allow minute volumes of up to $8 \mathrm{~L}$. to be recorded. During intermittent flow there is an error of measurement ranging from -2.8 per cent for rates of breathing up to 100 per minute, to +5 per cent for rates between 100 and 200 per minute. Calibration of the pneumotachograph and integrator can be carried out using a syringe. When compared with room air, 50 per cent nitrous-oxide-oxygen gives a similar integrator deflection, enabling this gas mixture to be used during the period of study without the need to apply a gas viscosity correction factor to the integrator deflection obtained.

\section{ACKNOWLEDGMENTS}

I wish to thank Dr. G. Jackson Rees for suggesting that the Lunn Pneumotachograph might be suitable for use during controlled ventilation. I am indebted to Dr. R. S. Jones, Department of Child Health, University of Liverpool, for granting me the facilities necessary for carrying out this work. I also thank Mr. John Martin, Department of Engineering, Alder Hey Hospital, Mr. M. C. K. Tweedie, Department of Mathematical Studies, University of Liverpool, and Mr. Douglas J. Kidd, Artist to the Faculty of Medicine in the University of Liverpool for their helpful contributions. To Dr. Aleck Hobbes I extend my gratitude for 
his advice on numerous occasions. My thanks are also due to Miss Virginia Larkins, Research Institute, Hospital for Sick Children, Toronto, for secretarial assistance.

\section{RÉSUMÉ}

On a étudié un pneumotachographe pour déterminer s'il convient de l'utiliser pour l'hyperventilation pulmonaire contrôlée. La baisse de pression à travers l'instrument est assez stable par unité de débit pour permettre d'enregistrer des volumes minute jusqu'à huit litres. Durant un débit intermittent, il y a une erreur de calcul qui va de -2.8 pour cent lorsque la respiration est de 100 ou moins par minute, jusqu’à +5 pour cent lorsque la respiration est de 100 à 200 par minute.

\section{REFERENCES}

1. Wricht, B. M. A Respiratory Anemometer. J. Physiol. 127: 25 (1955).

2. $\longrightarrow$ Symposium on Pulmonary Ventilation. R. P. Harbord and R. Woolmer, ed. Published for Brit. J. Anaesth. by John Sherrat \& Sons, Altrincham.

3. NunN, J. F. \& EzI-Asin, T. I. The Accuracy of the Respirometer and Ventigrator. Brit. J. Anaesth. 34: 422 (1962).

4. Hari, K. D. \& Reesen, F. H. Calibration of Wright Spirometer. Anesthesiology 23: 126 (1962).

5. Lunv, J. N.; Molyneux, L.; \& Pasx, E. A. A Device for the Measurement of Ventilation in Young Children under General Anaesthesia. Anaesthesia. 20: 135 (1965).

6. Sur.rivan, R. R. Further Study of the Flow of Air through Porous Media. J. Appl. Physiol. 12: $503(1941)$.

7. Rexnouds, O. Papers on Mechanical and Physical Subjects. 2: 51, 105. Cambridge (1901).

8. HILL, D. W. The Rapid Measurement of Respiratory Pressures and Volumes. Brit. J. Anaesth. 31: 352 (1959).

9. Hobnes, A. A Comparison of Methods of Calibrating the Pneumotachograph. Brit. J. Anaesth. 37: 987 (1965).

10. Smrtr, W. D. A. The Performance of a Walton Five Anaesthetic Machine. Brit. J. Anaesth. 33: 440 (1961).

11. Tweenme, M. C. K. Personal communication (1966). 